\title{
Aspectos da Comunicação Acerca da Sexualidade e a Surdez: um Estudo Comparativo de Sinais Entre Libras e American Sign Language para a Produção de Material Didático de Relevância para a Saúde da Mulher Surda
}

\author{
Merçon, Thays; Santos, Dilvani Oliveira; Delou, Cristina Maria Carvalho; Braz, \\ Ruth Maria Mariani; Castro, Helena Carla \\ Universidade Federal Fluminense - UFF — thaysmercon@gmail.com
}

Introdução: a sexualidade e a saúde do adolescente e da mulher têm sido colocadas na ordem da política educacional, devido ao nível crescente de portadores de doenças sexualmente transmissíveis (DSTs) e alta incidência de gravidez na adolescência, que é um fator relacionado ao mau desempenho e evasão escolar. Neste contexto inclui-se a comunidade surda, cujo acesso as campanhas educativas veiculadas a mídia fica comprometido pelo uso exclusivo da língua portuguesa. Assim, o ensino e o debate sobre a sexualidade e as DSTs envolvendo os surdos se inicia pela análise da existência de sinais que permitam uma abordagem apropriada e livre de mistificações. Objetivos: Neste trabalho temos como objetivo comparar os sinais existentes sobre o tema Sexualidade presentes na LIBRAS e compara-los com o American Sign Language, no intuito de estabelecer a necessidade de surgimento de novos sinais para criação de um material que aborde a saúde da mulher e suas especificidades, contribuindo para difundir os conceitos envolvendo este contexto, permitindo o acesso ao conhecimento e a cidadania pelo publico feminino surdo. Métodos: Realizamos a comparação dos sinais que abordam o tema sexualidade na Língua Brasileira de Sinais - LIBRAS utilizando como fonte de busca o Dicionário online Acesso Brasil e aqueles existentes na American Sign Language - ASL, presentes na $23^{\text {a }}$ edição do livro "Signs Of Sexual Behavior, An Introduction To Some Sex-Related Vocabulary In American Sign Language" resultante da pesquisa do Dr. James Woodward, Professor Associado de Linguística e Inglês pela Universidade de Gallaudet em Washington. Resultados: a análise de 92 palavras/sinais existentes no livro revelou que 49 delas não estão presentes no dicionário multimídia de LIBRAS com um percentual maior que $50 \%$ de ausência de termos. Os sinais representando as partes do corpo como pênis e vagina estão presentes, enquanto outros como coito interrompido, sífilis e diafragma não foram encontrados. Conclusões: a inserção de termos envolvendo este tema pode auxiliar no suporte oferecido aos jovens adolescentes por médicos e profissionais de ensino. Vale a pena ressaltar que a ausência dos sinais no dicionário multimídia, não determina a ausência na LIBRAS formal ou informal, mas aponta para a necessidade de um estudo mais detalhado desta questão, que deve ser tratada como de importância na saúde pública envolvendo a comunidade surda.

\footnotetext{
Merçon, Thays; Santos, Dilvani Oliveira; Delou, Cristina Maria Carvalho; Braz, Ruth Maria Mariani; Castro, Helena Carla. Aspectos da Comunicação Acerca da Sexualidade e a Surdez: um Estudo Comparativo de Sinais Entre Libras e American Sign Language para a Produção de Material Didático de Relevância para a Saúde da Mulher Surda. In: Anais do Congresso Internacional de Humanidades \& Humanização em Saúde [= Blucher Medical Proceedings, num.2, vol.1]. São Paulo: Editora Blucher, 2014. ISSN 2357-7282 DOI 10.5151/medpro-cihhs-10212
} 